\title{
NEGÓCIOS JURÍDICOS PROCESSUAIS: O NOVO PROTAGONISMO DAS PARTES DENTRO DA RELAÇÃO PROCESSUAL E O PAPEL DO JUIZ
}

\section{ARTIGO DE REVISÃO}

BUCCO, Bruna Maiolino ${ }^{1}$

BUCCO, Bruna Maiolino. Negócios Jurídicos Processuais: O novo protagonismo das partes dentro da relação processual e o papel do juiz. Revista Científica Multidisciplinar Núcleo do Conhecimento. Ano 06, Ed. 01, Vol. 05, pp. 144-157. Janeiro de 2021. ISSN: 2448-0959, Link de acesso: https://www.nucleodoconhecimento.com.br/lei/negocios-juridicos

\section{RESUMO}

O Direito Processual brasileiro enfrentou diversas modificações e ampliações com a entrada em vigor do Novo Código de Processo Civil no ano de 2016. Alguns institutos já existentes foram revisitados, de modo a se adequarem aos preceitos fundamentais que passaram a ser expressamente previstos no CPC/15. Dentre eles está o negócio jurídico processual. O CPC/15 manteve os negócios processuais típicos, já presentes no CPC/73, e alargou o espectro, trazendo no art. 190 do CPC previsão sobre a possibilidade da realização de convenções processuais atípicas. Por essa razão, em decorrência do surgimento desta nova espécie de ato, nosso estudo objetivou, através da análise e interpretação de bibliografias disponíveis sobre o tema, investigar a participação do juiz frente a dilação da autonomia e da liberdade dada às partes no processo. Conseguimos identificar que, em algumas situações, a manifestação de vontade do magistrado se mostra imprescindível para que o negócio processual seja

\footnotetext{
${ }^{1}$ Graduada em Direito pela UFRJ, pós graduada em direito e processo penal pela UCAM, pós graduada em direito processual civil aplicado pela EBRADI.
} 
válido, sem que isso represente afronta ao art. 190 do CPC/15, nem tão pouco ao princípio do auto regramento da vontade das partes.

Palavras- chave: negócios jurídicos processuais atípicos, protagonismo das partes, atuação do juiz, validade das convenções.

\section{CONSIDERAÇÕES INTRODUTÓRIAS}

Passados alguns anos da entrada em vigor do Código de Processo Civil de 2015, muitos debates e reflexões ainda permeiam a comunidade processualista quanto aos contornos dados pelo novo diploma processual a institutos, muitas vezes, já conhecidos.

O publicismo que sempre regeu as normas processuais mostrava-se como um óbice a alterações procedimentais propostas pelas partes, já que estas normas eram tradicionalmente entendidas como cogentes.

Contudo, já se encontravam presentes no $\mathrm{CPC} / 73$ os negócios jurídicos processuais, os quais ganharam uma nova amplitude com a chegada do novo Código de Processo Civil. O antigo CPC continha a previsão de algumas hipóteses de negócios processuais típicos, como: a eleição de foro, as convenções sobre o ônus da prova e da suspensão do processo, entretanto, o CPC/15 inovou ao trazer em seu art. 190 a possibilidade de celebração dos negócios jurídicos atípicos (AURELLI, 2017), fundada no princípio da cooperação e da adequação. Consagrou, portanto, três novidades significativas: o princípio da adequação procedimental, a cláusula geral de atipicidade de negócios processuais e o princípio do respeito ao autorregramento da vontade das partes (POMJÉ, 2017).

Com essa previsão, abriu-se a possibilidade de negociação em todos os campos do direito processual, como: produção probatória, cumprimento de sentença, prazos processuais; sem ficarem os litigantes adstritos apenas às convenções processuais típicas, podendo as partes, ainda, transacionar sobre questões que envolvam 
procedimento, como ocorre com as convenções sobre ritos mais curtos, para simplificar as causas (FERNANDES, 2017).

Com tantas mudanças advindas do Novo Código, passou-se a questionar qual seria, então, o papel do juiz frente a todo esse novo movimento que se mostrava no $\mathrm{CPC} / 15$, e que trouxe maior protagonismo às partes com o objetivo primordial de imprimir mais efetividade ao processo e, em alguns casos, celeridade.

Teria o publicismo das normas processuais dado lugar ao privatismo, tão comum no Direito Civil?

Dentre toda a gama de negócios jurídicos processuais que se tornaram possíveis com o novo diploma processual, vemos a necessidade de atuação do juiz para a validade desses atos alterar-se, a depender do tipo de convenção processual que se estabelece, firmando uma nova relação com as partes e com o processo. Seria ele, nestes casos, parte no processo? Estaria o art. 190, caput do CPC/15 também direcionado ao magistrado?

\section{PANORÂMA DOS NEGÓCIOS JURÍDICOS PROCESSUAIS NO $\mathrm{CPC} / 15$}

Consoante Mouzalas; Terceiro Neto e Madruga (2016, p.303) "a noção de negócio jurídico processual deriva da própria noção de negócio associado à de ato processual". O negócio jurídico, em conjunto com o ato jurídico stricto sensu, são espécies do gênero ato jurídico lato sensu. A diferença entre ambos repousa no fato de que neste, os efeitos são previamente estabelecidos e inalteráveis pela vontade das partes, enquanto naquele, há a permissão do direito para que, em certos limites, as partes regrem seus interesses, conforme suas conveniências.

O instituto dos negócios processuais não é uma novidade trazida pelo novo diploma processual vigente, tendo em vista já constar no CPC/73. A novidade encontra-se na possibilidade de realização desses negócios de forma atípica, previsão esta que trouxe uma atuação mais ampla e efetiva para as partes dentro do processo. 
Entretanto, antes de adentrarmos às minúcias do tema, importa salientar que os preceitos fundamentais também permeiam a aplicação das convenções processuais e devem ser observados, em especial o princípio da cooperação, encartado no art. 6 do $\mathrm{CPC} / 15$, já que garante "às partes um maior protagonismo na realização do processo, proporcionando a elas oportunidade e participação ativa na solução dos conflitos e efetividade da tutela." (AURELLI, 2017, p.48). Efetividade esta que também é apresentada como um dos corolários do novo Código de Processo Civil, dado que todos os sujeitos processuais devem, através do princípio da cooperação, buscar sempre como objetivo final decisões de mérito justas e efetivas, proferidas em um tempo razoável.

A doutrina separa as convenções atípicas em duas espécies: aquelas que alteram o procedimento (prazos, perícias, audiências) e aquelas que alteram o regime jurídico das partes (ônus, deveres, poderes, faculdades). A lei restringiu apenas aos negócios que tratam sobre procedimento a necessidade de adequação às especificidades do conflito, não sendo necessariamente exigidos quando se tratar de acordos processuais que versem sobre regime jurídico das partes. Contudo, não há impedimentos para que ambos os tipos sejam rejeitados se identificada futilidade ou inadequação fundadas no desrespeito a boa-fé, a função social ou a qualquer normal fundamental do $\mathrm{CPC} / 15$, conforme veremos mais à frente (BANDEIRA, 2015).

Com relação às classificações, dentre muitas que os negócios jurídicos processuais podem receber, possui especial relevo a classificação quanto à tipicidade, que se divide em negócios processuais típicos e atípicos. Os típicos são aqueles que têm sua previsão constante na lei, sendo prescindível qualquer atuação das partes quanto a sua regulação (CUNHA, 2015).

Como exemplos de negócios jurídicos típicos no CPC/15 temos: a eleição de foro (art. 63 do CPC/15); a prorrogação de competência (art. 65 do CPC/15); o calendário para a prática de atos processuais (art. 191 do CPC/15); a renúncia de prazo (art. 225 do CPC/15); a suspensão do processo (art. 313, II do CPC/15) e a organização processual (art. 357, $2^{\circ}{ }^{\circ}$ do $\mathrm{CPC} / 15$ ). 
Já os negócios jurídicos atípicos estão expressamente previstos no art. 190 do CPC, que é uma norma geral para os negócios processuais e prevê

Versando o processo sobre direitos que admitam autocomposição, é lícito às partes plenamente capazes estipular mudanças no procedimento para ajustá-lo às especificidades da causa e convencionar sobre os seus ônus, poderes, faculdades e deveres processuais, antes ou durante o processo.

$\mathrm{Na}$ verdade, o Novo Código de Processo Civil trouxe uma gama de normas que abordam a negociação sobre o processo. Segundo Didier Jr. (2017, p.169) "o art. 190 e o art. 200 do CPC são o núcleo de microssistema e devem ser interpretados conjuntamente, pois restabelecem o modelo dogmático de negociação sobre o processo no direito processual civil brasileiro."

Assim, podemos inferir da dicção do artigo 190 que o novo CPC "prevê a possibilidade de as partes, desde que plenamente capazes e em causa que verse sobre direitos que admitam a autocomposição, estipularem mudanças no procedimento para ajustálo às especificidades da causa" (NEVES, 2016), criando, nessa toada, uma cláusula geral de negociação, que traz autonomia e independência para as parte convencionarem fora do previsto nos negócios processuais típicos.

Outra importante classificação está ligada à vontade das partes na realização do negócio jurídico processual. Parcela da doutrina considera a existência de negócios processuais unilaterais quando da renúncia e do reconhecimento do pedido. Já o art. 190 do novo CPC carrega em si a previsão dos negócios jurídicos processuais bilaterais, sendo imprescindível o acordo de vontade das partes para a sua perfectibilização. E, por fim, há a possibilidade de o negócio processual ser plurilateral, quando o acordo se dá não só entre as partes, mas também com o órgão jurisdicional envolvido (juiz ou tribunal), como podemos observar com a calendarização do procedimento, no art. 191 do CPC/15 ou com o saneamento compartilhado, previsto no art. $357, \S 3^{\circ}$ do CPC/15 "(NEVES, 2016, p.303).

Avançando no tema, o acordo previsto no art. 190 do CPC/15 tem a possibilidade de ser realizado tanto processualmente, quanto pré-processualmente. Se feito antes do 
início do processo, pode-se dar por cláusula contratual ou por instrumento em separado, ao passo que se firmado ao longo do processo, poderá ser feito extrajudicialmente e protocolado em juízo ou judicialmente, na presença do magistrado ou do conciliador/mediador " (idem, p. 306/307).

Ademais, a regra é que, versando o processo sobre direitos que admitam autocomposição, não se faz necessária a homologação judicial do negócio jurídico processual firmado para que ele se mostre eficaz, devendo, entretanto, se submeter ao controle de validade pelo juiz, recusando aplicação nos casos em que haja nulidade, ou se inserido abusivamente em contrato de adesão, ou ainda se uma das partes se mostrar manifestamente vulnerável.

Conquanto a previsão do art. 190 do CPC/15 esteja adstrita a direitos que admitam autocomposição, a doutrina é unânime em entender que o dispositivo legal é perfeitamente aplicável a direitos indisponíveis, desde que a parte protegida pela indisponibilidade seja a beneficiada, vendando-se o contrário (MOUZALAS; TERCEIRO NETO; MADRUGA, 2016). Isso porque não se há de confundir direitos indisponíveis com direitos que não admitem autocomposição, em razão da autocomposição não ter como objetivo o direito material, mas sim as formas de se exercer o direito, como, por exemplo, os modos e os cumprimentos da obrigação.

Fruto dessa relevante distinção, se originou a possibilidade de aplicação das convenções processuais aos processos coletivos, mesmo que tratem de direito indisponíveis e que tenham o Ministério Público como parte na ação (NEVES, 2016). Neste sentido é o entendimento do Fórum de Processualista Civis, nos enunciados 253 e 255 (Enunciado 253 do FPPC: "O Ministério Público pode celebrar negócio processual quando atua como parte."; enunciado 255 do FPPC: "É admissível a celebração de convenção processual coletiva.").

\section{LIMITES AOS NEGÓCIOS JURÍDICOS PROCESSUAIS}

Pela leitura atenta do novo Código de Processo Civil é fácil identificar que houve uma ampliação da liberdade das partes em convencionar sobre o procedimento ou a 
situação das posições processuais, o que torna o processo mais democrático e eficaz, alcançando os objetivos almejados pelos litigantes em menor tempo. Entretanto, os benefícios alcançados com o aumento das possibilidades de uso das convenções processuais não podem ser justificativas suficientes para que elas sejam transacionadas de forma indiscriminada, sem a observância de limites.

Nesta toada, a doutrina vem entendendo que as normas fundamentais são limitações precípuas ao poder das partes em estabelecer negócios jurídicos processuais. Isto porque, essas convenções não podem violar as garantias mínimas do processo, ou seja, não podem afrontar o devido processo legal.

O princípio da boa-fé permeia todo o ordenamento jurídico pátrio, inclusive as normas processuais. Previsto expressamente no art. $5^{\circ}$ do $\mathrm{CPC} / 15$, não é permitido às partes afastar os seus deveres de boa-fé e lealdade processual, devendo agir com probidade e retidão em todas as suas manifestações, o que permite ao juiz, neste momento, atuar de modo a coibir que atos processuais negociados despidos de boa-fé processual sejam praticados (idem, p. 311).

Outrossim, outra limitação prevista pela doutrina se encontra no princípio da publicidade, pois não seria permitido às partes afastar a publicidade dos atos praticados, estabelecendo novas hipóteses de segredo de justiça ou então afastar as hipóteses previstas do caso concreto. Assim, considera-se que o art. 11 do CPC/15 é absoluto, não podendo ser inaplicado por convenção das partes.

Da mesma forma, não é permitido às partes afastar a aplicação de normas cogentes. Como pressuposto destas, tem-se que elas são impostas pela lei aos sujeitos processuais, não podendo, assim, as partes realizarem acordo de vontade com relação a aplicação ou não de tais normas.

Como exemplos da impossibilidade de alteração de normas cogentes em decorrência de acordo de vontade entre as partes, Daniel A. A. Neves (2016, p.313) esclarece

Com o fundamento de que as partes não podem afastar normas cogentes, não se admite que verse sobre a admissão de prova ilícita, 
para excluir a participação do Ministério Público quando a lei exige sua presença, para fixar prioridade de julgamento quando previsto em lei, para criar novos recursos ou ampliar sua hipótese de cabimento, para modificar regra de competência absoluta, para criar hipótese de ação rescisória e de outras medidas tendentes a desconstituir a coisa julgada, para a dispensa da presença de litisconsortes necessários etc.

Contudo, não é fácil definir as limitações a que o acordo de vontade nas convenções processuais está submetido, sendo necessário um trabalho constante da jurisprudência e da doutrina para definir tais limites, tendo por base as normas fundamentais do CPC/15 e a leitura constitucional do processo.

Por essa razão, tornaram-se tão importantes tanto os Enunciados do Fórum Permanente de Processualistas Civis (FPPC), quanto os Enunciados da Escola de Formação dos Magistrados (ENFAM), que se ocuparam em indicar, casuisticamente, hipóteses em que pode ou não ser utilizado o negócio jurídico processual.

Para o FPPC são admissíveis: pacto de impenhorabilidade; acordo de ampliação de prazos das partes de qualquer natureza; acordo de rateio de despesas processuais; dispensa consensual de assistente técnico; acordo para retirar o efeito suspensivo de recurso; acordo para não promover execução provisória; pacto de mediação ou conciliação extrajudicial ou de mediação prevista no art. 334; pacto de exclusão contratual da audiência de conciliação ou de mediação prevista no at. 334; pacto de disponibilização prévia de documentação (pacto de disclosure), inclusive com estipulação de sanção negocial, sem prejuízo de medidas coercitivas, mandamentais, sub-rogatórias ou indutivas; previsão de meios alternativos de comunicação das partes entre si; acordo para realização de sustentação oral; acordo para ampliação do tempo de sustentação oral; julgamento antecipado do mérito convencional; convenção sobre prova; redução de prazos processuais, para dispensar caução no cumprimento provisório de sentença (Enunciados 19, 21 e 262).

Para o FPPC, são inadmissíveis os negócios jurídicos para modificação da competência absoluta; acordo para supressão da primeira instância, de exclução do Ministério Público, vedação da participação do amicus curiae (Enunciados 20, 253 e 392).

Para a ENFAM, são inadmissíveis os negócios jurídicos que afetem poderes do juiz, tais como os que: limitem seus poderes de instrução ou de sanção à litigância ímproba; subtraiam do Estado-juiz o controle da legitimidade das partes ou do ingresso de amicus curiae; introduzem 
novas hipóteses de irrecorribilidade, de rescisória ou de sustentação oral não previstas em lei; estipulem o julgamento do conflito com base em lei diversa da nacional vigente; e estabeleçam prioridade de julgamento não prevista em lei (Enunciado 36). E são nulas, por ilicitude do objeto, as convenções processuais que violem as garantias constitucionais do processo, tais como as que: autorizem o uso de prova ilícita; limitem a publicidade do processo para além das hipóteses expressamente previstas em lei; modifiquem o regime de competência absoluta; e dispensem o dever de motivação (Enunciado 37) (NEVES, 2016, p. 316/317).

\section{O PAPEL DO JUIZ FRENTE AO ACORDO DEFINIDO NO NEGÓCIO JURÍDICO PROCESSUAL}

Muito se discute na atualidade o papel do órgão julgador frente à aplicação do art. 190 do CPC/15 e se isso representaria uma limitação aos poderes do juiz, aqui entendidos tanto os magistrados de primeiro grau, quanto os tribunais.

Retomando-se o entendimento das normas processuais à luz do $\mathrm{CPC} / 73$, estas eram tidas como predominantemente cogentes, ou seja, eram inalteráveis, quer pelos litigantes, quer pelo magistrado, não sendo possível a convenção sobre procedimentos ou sobre o regime jurídico das partes. Porém, o direito processual civil também é regido pelo campo da liberdade, muito embora faça parte do direito público, e que, sob a influência da autonomia que os demandantes têm de transacionar na seara do direito material, aumentou os poderes destes para a celebração de convenções processuais (POMJÉ, 2017), culminando na previsão expressa do CPC/15 sobre a possibilidade da realização de negócios processuais atípicos.

Nas palavras de Pedro Henrique Nogueira: "Os negócios processuais já existiam sob a égide da legislação antecedente, mas nunca se teve tamanho espaço de participação dos litigantes no desenrolar da atividade jurisdicional, a ponto de possibilitar que as partes construam, negocialmente, o próprio procedimento." (NOGUEIRA, 2016, p. 255).

Como bem se sabe, a regra erigida no Novo CPC dispensa a homologação judicial para a validade das convenções processuais, podendo ser exigida, entretanto, para 
negócios processuais que visem mudanças no procedimento, como se vê nos casos de desistência (art. 200, §ú do CPC) e de organização consensual do processo (art. 357, §2 do CPC).

Nesta feita, o negócio jurídico processual restará caracterizado pela vontade de as partes praticarem o ato, somado à vontade delas de produzir um determinado efeito jurídico. Escolhe-se um regramento jurídico para determinada situação específica (DIDIER JR., 2017, p. 169). São negócios processuais que não interferem na situação jurídica titularizada pelo juiz, uma vez que a atuação deste se mostra prescindível para que esses atos preencham seus requisitos de validade.

Excepcionalmente, como já exposto, alguns atos eleitos pelas partes necessitarão de homologação judicial para que produzam seus efeitos no processo, porém todos os negócios jurídicos processuais passarão pelo crivo do juiz quanto a verificação da sua validade dentro do ordenamento jurídico, sendo indispensável a presença de três requisitos: os celebrantes têm que ser capazes; o objeto tem que ser lícito e devem observar forma prescrita ou não proibida por lei (arts. 104, 166 e 167, todos do CC).

Ademais, convém mencionar a previsão contida no art. 190, §ú do CPC, a qual permite que o juiz, a requerimento ou ex officio, desconsidere a convenção que seja inválida ou abusiva, exercendo, assim, o controle de validade sobre as convenções processuais. Deve, todavia, observar a regra geral sobre as invalidades processuais, e somente declará-la nula se comprovado o prejuízo (ALMEIDA, 2014).

Faz-se mister ainda, que o juiz observe dois requisitos negativos para validar um ato: a abusividade e a situação jurídica titularizada pelo magistrado. Consoante Avelino (2016, p. 331) “(...) se o negócio sobre o procedimento está apto a influenciar, de forma ilegítima, a atuação do juiz no processo, o controle sobre a sua validade deve ter resultado negativo."

O controle de validade previsto pelo art. 190, §ú do CPC é vinculado e não discricionário, apenas autorizando ao juiz que realize o controle para impedir que as partes extrapolem o poder que Ihes é conferido pelo dispositivo, garantindo que elas 
permaneçam dentro dos limites autorizados pelo auto regramento da vontade. A previsão também se destina a proibir o juiz de contrariar aquilo que foi transacionado, devendo ele agir proativamente no intuito de implementar o negócio processual acordado.

Noutro giro, em algumas situações, a lei impõe a necessidade de manifestação de vontade do magistrado para que a convenção processual se perfectibilize. Aqui este também se mostra como um sujeito do ato. Logo, para que adentre ao plano da validade, é imprescindível que o juiz se manifeste positivamente pela formação do negócio processual, pois se trata de convenção processual plurilateral.

Importante notar a distinção existente entre a titularização de direitos quanto ao processo e quanto ao direito material objeto da lide. Vejamos:

que, quando o legislador permite que sejam efetivados negócios jurídicos a respeito de "direito que admitam autocomposição", deixa entendido que a hipótese do art. 190 (atipicidade dos negócios processuais) não se aplica ao juiz, pois ele não titulariza pessoalmente direito (no sentido de situação jurídica substantiva subjetiva) posto em debate como objeto do processo, na medida em que atua como órgão da jurisdição. É preciso diferenciar: as partes titularizam situações jurídicas relativas tanto ao processo (entendido como procedimento em contraditório-ônus, poderes, deveres, faculdades, etc.) quanto ao direito material objeto da relação jurídica processual; o juiz titulariza situações jurídicas relativas ao processo (inserido no procedimento em contraditório), mas não em relação ao direito material que se discute (idem, p. 333).

Uma grande discussão sobre a participação do juiz na formação do negócio processual, travada no âmbito doutrinário, está ligada ao fato de o art. 190, caput do $\mathrm{CPC} / 15$ tratar apenas sobre convenções processuais celebradas pelas partes. Fredie Didier Jr. (2017, p.169) entende que além de haver negócios jurídicos processuais típicos envolvendo o juiz, não há qualquer prejuízo a pactuação do ato atípico a coparticipação do magistrado, pontuando ainda que "(...) poder negociar sem a interferência do juiz é mais do que poder negociar com a participação do juiz."

Outros, como Avelino (2016, p.334), consideram que o disposto no art. 190 do CPC se refere expressamente às partes e que a legitimidade para o juiz atuar como co 
declarante em um negócio jurídico processual não encontraria respaldo na lei, mas sim no princípio da adequação, já que "o princípio da adequação serve à adaptação do procedimento quando necessária à plena efetividade da tutela estatal do direito material."

Há ainda aqueles que, na esteira de Antônio do Passo Cabral (2016), não consideram o magistrado como parte do negócio processual, pois este não possuiria autonomia ou liberdade para transacionar, já que não estampa capacidade de negociação. Para o autor, o juiz não pode ser parte integrante do negócio processual, somente as partes, cabendo a ele apenas homologá-lo ou admiti-lo através do controle de sua validade.

A propósito das convenções processuais típicas plurilaterais, temos como principais exemplos o calendário processual (art. 191 do CPC) e a organização compartilhada do processo (art. 357, $3^{\circ}$ do CPC).

No calendário, as partes, em conjunto com o juiz, pré-fixam as datas em que os atos serão realizados, dispensando-se assim futuras intimações para a prática dos atos e audiências previstos no calendário. Com isto, vinculam-se todos os personagens do processo, inclusive terceiros intervenientes (CUNHA, 2017). O juízo como um todo fica subordinado à tratativa processual estabelecida, pois mesmo que o magistrado seja substituído por outro, a observância do calendário continua a ser obrigatória pelo novo juiz.

Já no que se refere a organização compartilhada do processo, da dicção do art. 357, $\S 3^{\circ}$ do CPC se extrai que para que se dê o saneamento compartilhado, a causa tem que ser complexa, assim, "a decisão de saneamento é um ato complexo que, para ser válido, exige a participação do magistrado e das partes em contraditório. Aqui a necessidade de participação das partes e do juiz também se encontra no plano da validade do ato, pois todos sujeitos do negócio." (AVELINO, 2016, p.336).

Quanto aos negócios processuais atípicos plurilaterais, o tema ainda é bastante novo, carecendo de digressões mais profundas sobre ele, porém o Fórum Permanente de Processualistas Civis, em seu Enunciado no 21 prevê que "São admissíveis os 
seguintes negócios, dentre outros: acordo para realização de sustentação oral, acordo para ampliação do tempo de sustentação oral, julgamento antecipado do mérito convencional, convenção sobre prova, redução de prazos processuais."

\section{SÍNTESE CONCLUSIVA}

Todo o exposto ao longo desse breve ensaio nos leva a perceber que o novo Código de Processo Civil consagrou a liberdade das partes dentro do processo.

Percebe-se com facilidade que a intenção do legislador foi permitir um maior atuar das partes em busca da efetividade do processo como instrumento hábil a alcançar uma decisão de mérito mais célere e justa.

Neste sentido, o princípio da cooperação ganha especial relevo, pois apresenta-se como arcabouço, juntamente com os demais preceitos fundamentais do CPC/15, para a ampliação dos negócios jurídicos processuais.

Consoante previsto no $\mathrm{CPC} / 73$, os negócios processuais típicos já permitiam às partes acordarem sobre questões processuais, mesmo diante do publicismo e da cogência dessas normas. Entretanto, somente com a entrada em vigor do Novo Código de Processo, a posição das partes dentro da marcha processual foi erigida a um patamar de maior relevância, sendo-Ihes permitida a realização de convenções processuais atípicas.

$\mathrm{O}$ art. 190 do $\mathrm{CPC} / 15$ trouxe a regra geral sobre negócios jurídicos processuais atípicos, abrindo as portas para que diversas espécies de negócios processuais sejam firmadas. A título exemplificativos podemos citar o acordo de impenhorabilidade, o acordo de despesas processuais, a dispensa consensual de assistente técnico, dentre outros.

A princípio, respeitado o auto regramento da vontade e os limites impostos pelo art. 190 do CPC, cabe aos litigantes transacionar sobre questões processuais sem que haja a participação do juiz, devendo este atuar apenas nos casos em seja necessária 
a homologação e sempre para verificar a validade das convenções processuais apresentadas.

Entretanto, surge uma divergência na doutrina quanto aos negócios em que é imprescindível a manifestação de vontade do juiz para que este seja válido. Entendemos que o ordenamento jurídico pátrio não apresenta óbices quanto a necessidade de concordância do juiz com as partes para que certos atos se formem, se essa convergência de vontades for fundamental para o alcance dos requisitos de validade do negócio jurídico.

O fato de o art. 190 do CPC ter ampliado os poderes das partes, dando-lhe mais autonomia e liberdade para transacionar processualmente, não significa um impedimento para a atuação do magistrado.

\section{REFERÊNCIAS BIBLIOGRÁFICAS}

ALMEIDA, Diogo Assumpção Rezende. Das convenções processuais no processo civil. Tese (Doutorado em Direito Processual)- Faculdade de Direito, Universidade do Estado do Rio de Janeiro, Rio de Janeiro, 2014.

AURELLI, Arlete Inês, Análise e Limites da Celebração de Negócios Jurídicos Processuais na Execução por Título Extrajudicial e/ou Cumprimento de Sentença. In: MARCATO, Ana; GALINDO, Beatriz; GOÉS, Gisele Fernandes; BRAGA, Paula Sarno; APRIGLIANO, Ricardo; NOLASCO, Rita Dias. (Coords.) Negócios Processuais, v.1. Salvador: Juspodivm, 2017.

AVELINO, Murilo Teixeira. A posição do magistrado em face dos negócios jurídicos processuais-já uma releitura. In: CABRAL, Antonio do Passo; NOGUEIRA, Pedro Henrique (Coords). Coleção Grandes Temas do novo CPC, v.1, $2^{a}$ ed., Salvador: Juspodivm, 2016.

BANDEIRA, Carlos Adriano Miranda, O papel do juiz no controle dos negócios jurídicos processuais e o art. 190 do Novo Código de Processo Civil. 2015. Disponível em https://revista.jfpe.jus.br/index.php/RJSJPE/article/viewFile/126/119. 
BRASIL. Lei 13.105, de 16 de março de 2015. Institui o Código de Processo Civil. Diário Oficial da União, Brasília, 17 mar 2015.

CABRAL, Antonio do Passo, Convenções processuais, n.4.3. Salvador: Juspodivm, 2016.

CUNHA, Leonardo Carneiro da, Calendário processual: negócio típico previsto no art. 191 do CPC. In: MARCATO, Ana; GALINDO, Beatriz; GOÉS, Gisele Fernandes; BRAGA, Paula Sarno; APRIGLIANO, Ricardo; NOLASCO, Rita Dias. (Coords.) Negócios Processuais, v.1. Salvador: Juspodivm, 2017.

CUNHA, Leonardo Carneiro da, Negócios jurídicos processuais no processo civil brasileiro. In: CABRAL, Antonio do Passo; NOGUEIRA, Pedro Henrique (Coords) Negócios processuais, Salvador: Juspodivm, 2015.

DIDIER JR., Fredie, Negócios jurídicos processuais atípicos no CPC-12015. In: MARCATO, Ana; GALINDO, Beatriz; GOÉS, Gisele Fernandes; BRAGA, Paula Sarno; APRIGLIANO, Ricardo; NOLASCO, Rita Dias. (Coords.) Negócios Processuais, v.1. Salvador: Juspodivm, 2017.

FERNANDES, Renata Assalim, Negócios jurídicos processuais no novo CPC - o que pode?. $2017 . \quad$ Disponível em https://www.migalhas.com.br/depeso/258990/negocios-juridicos-processuais-nonovo-cpc-o-que-pode.

MOUZALAS, Rinaldo; TERCEIRO NETO, João Otávio; MADRUGA, Eduardo; Processo Civil, vol. único - 8를 ed. rev., ampl., e atual.- Salvador: Juspodivm, 2016.

NEVES, Daniel Amorim Assumpção, Novo Código de Processo Civil Comentado, Salvador: Juspodivm, 2016.

NOGUEIRA, Pedro Henrique. Negócios Jurídicos Processuais. Salvador: Juspodivm, 2016. 
POMJÉ, Caroline, A mitigação da incidência do adágio iura novit curia em virtude das convenções processuais: breve análise do art. 357, §2ㄹ, do Código de Processo Civil. In: MARCATO, Ana; GALINDO, Beatriz; GOÉS, Gisele Fernandes; BRAGA, Paula Sarno; APRIGLIANO, Ricardo; NOLASCO, Rita Dias. (Coords.) Negócios Processuais, v.1. Salvador: Juspodivm, 2017.

Enviado: Outubro, 2020.

Aprovado: Janeiro, 2021. 